\title{
Depositional Facies Analysis Using Core Samples from Greater Ughelli Depobelt, Niger Delta Basin Nigeria
}

\section{*MAJU-OYOVWIKOWHE, GE; LUCAS, FA}

\author{
Department of Geology, University of Benin, Benin City. Nigeria \\ *Corresponding Author Email: efetobore.maju@uniben.edu
}

\begin{abstract}
Sedimentological analysis of core samples from Well XY-62 located within the greater Ughelli depobelt of the Niger Delta basin was carried out. Some physical deterioration had set in and some gaps had reduced the total core length available to $316.90 \mathrm{ft}$. The cores contain three sandstone and one mudrock lithofacies: Fine-grained mmscale laminated sandstone (Sl.f) 40.83\%, medium to coarse-grained cm-scale cross-bedded sandstone (Sx.m) $35.34 \%$, pebbly Sandstone (PS) 4.39\%, bedded Mudstone (Mb) 19.44\%. The sandstone lithofacies differ from one another mainly in grain size, as appears obvious, otherwise they are largely texturally, compositionally, diagenetically and structurally broadly similar. They are generally clean (zero to $20 \%$ clay content), moderately well to well sorted, pebbly, and texturally mature. Quartz appears to be the sole framework component, making the sandstones mineralogically mature i.e. quartz arenites and quartz wackes. Being generally weakly consolidated and scantily cemented, the sandstones are all in the early stages of diagenesis, an attribute that has had a desirable effect on their reservoir quality. The bedded mudstone lithofacies contains laminated claystones and fissile shales which are all thought to have compartmentalized the sand reservoirs rather than sealed them. Depositional environments have been inferred to be the foreshore setting, with lagoon subenvironments that favoured mudrock accumulation landward of a barrier bar complex. The overall motif read from both the strip log and the wireline logs indicate neither clear progradation nor unequivocal retrogradation of the lithofacies. It is therefore concluded that the XY- 62 cores were cut from an aggradational depositional setting.
\end{abstract}

DOI: https://dx.doi.org/10.4314/jasem.v23i6.22

Copyright: Copyright (C) 2019 Maju-Oyovwikowhe and Lucas. This is an open access article distributed under the Creative Commons Attribution License (CCL), which permits unrestricted use, distribution, and reproduction in any medium, provided the original work is properly cited.

Dates: Received: 01 April 2019; Revised: 09 May 2019; Accepted 21 June 2019

Keywords: Cores, Sediment analysis, Depositional environments, Niger Delta

The concept of interpreting rocks in terms of modern processes dates back to the 18 th and 19 th centuries (the present is the key to the past). The nature of sedimentary material is very varied in origin, size, shape and composition. Particles such as grains and pebbles may be derived from the erosion of older rocks or directly ejected from volcanoes. Organisms form a very important source of material, ranging from microbial filaments encrusted with calcium carbonate to whole or broken shells, coral reefs, bones and plant debris. Direct precipitation of minerals from solution in water also contributes to sediments in some situations. Formation of a body of sediment involves either the transport of particles to the site of deposition by gravity, water, air, ice or mass flows or the chemical or biological growth of the material in place. Accumulation of sediments in place is largely influenced by the chemistry, temperature and biological character of the setting. The processes of transport and deposition can be determined by looking at individual layers of sediment. The size, shape and distribution of particles all provide clues to the way in which the material was carried and deposited. Sedimentary structures such as ripples can be seen in sedimentary rocks and can be compared to ripples forming today, either in natural environments or in a laboratory tank. Assuming that the laws that govern physical and chemical processes have not changed through time, detailed measurements of sedimentary rocks can be used to make estimates (to varying degrees of accuracy) of the physical, chemical and biological conditions that existed at the time of sedimentation. These conditions may include the salinity, depth and flow velocity in lake or seawater, the strength and direction of the wind in a desert and the tidal range in a shallow marine setting. A depositional environment describes the combination of physical, chemical and biological processes associated with the deposition of a particular type of sediment and therefore the type of rock that forms after lithification. Therefore environment at any point on the land or under the sea can be characterized by the physical and chemical processes that are active there and the organisms that live under those conditions at that time. In the description of sedimentary rocks in terms of depositional environments, the term 'facies' is often used. A rock facies is a body of rock with specified characteristics that reflect the conditions under which

*Corresponding Author Email: efetobore.maju@uniben.edu 
it was formed (Reading and Levell 1996). Describing the facies of a body of sediment involves documenting all the characteristics of its lithology, texture, sedimentary structures and fossil content that can aid in determining the processes of formation. By recognizing associations of facies it is possible to establish the combinations of processes that were dominant; the characteristics of a depositional environment are determined by the processes that are present, and hence there is a link between facies associations and environments of deposition. Every depositional environment has a unique combination of processes, and the products of these processes, the sedimentary rocks, will be a similarly unique assemblage and by objectively considering each bed in terms of physical, chemical and biological processes, it is always possible to provide some indication of where and how a sedimentary rock was formed. Stratigraphy on the other hand has to do with the relationship of layered rocks with time. The stratigrapher is concerned with the observation, description and interpretation of direct and tangible evidence in rocks to determine the history of such a rock. A merging of Sedimentology and stratigraphy allows us to build up pictures of the Earth's surface at different times in different places and relate them to each other. The objective of this study is to identify sedimentary facies based on their physical properties and determine the energy regime during deposition of sediments.

\section{MATERIALS AND METHODS}

Description of study area: Well XY-62 was drilled within OML 30 located in the Greater Ughelli depobelt of the Niger Delta. It is a vertical development well with a TD of $10105 \mathrm{ft}$ subsea. The cores were cut between 7015 and $9678 \mathrm{ft}$ with long uncored intervals.

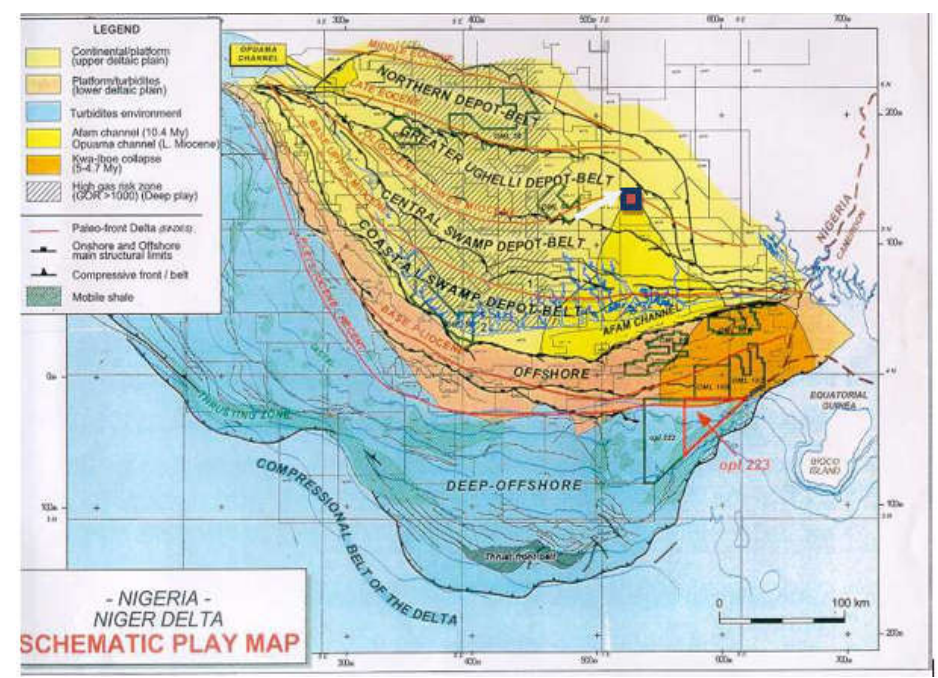

Fig 1: Section map of Nigeria showing the study area (dark blue square) and Depobelts that make up the Niger Delta Basin (modified from Nwozor et al., 2012)

Geological Review of the Niger Delta Basin: The Niger Delta Basin is also known as the Niger Delta province. It is an extensional rift basin located between the Niger Delta and the Gulf of Guinea on the Passive Continental Margin near the Western Coast of Nigeria with suspected access to Cameroon, Equatorial Guinea and Sao Tome and Principe. The Basin is very complex and carries very high economic value as it contains a very productive petroleum system. The Niger Delta Basin is one of the largest subarea basins in Africa. It has a subarea of about $75,00 \mathrm{~km}^{2}$, a total area of $300,000 \mathrm{~km}^{2}$ and a sediment fill of about $500,000 \mathrm{~km}^{3}$, a depth of about 9 to $12 \mathrm{~km}$. It is composed of several different geologic formations that indicate how the basin could have been formed as well as the regional tectonic of the area. The Niger-Delta lies in the South-Western part of a larger tectonic structure, the Benue Trough. The other side is bounded by the Cameroon Volcanic Line and the Transform, Passive Continental Margin. The sedimentation pattern in the Niger Delta basin has been a site of cyclic sedimentation. The tertiary paralic sediments are composed of several depositional cycles with thickness ranging from 50-300ft, although cycles exceeding $300 \mathrm{ft}$ are less common. The Complete cycle consists of thin fossiliferous transgressive marine sand followed by an offlap sequence of marine shale and laminated fluviomarine sediments (Weber 1971).

Stratigraphy of the Niger Delta Basin: The stratigraphy of the southern Nigeria basin has been described in some detail by Short and Stauble (1967) 
and Reyment (1965). The deposits were laid down during a predominantly marine depositional cycle. The first phase was concluded by a phase of folding, faulting and uplift occurring during the Santonian time and affecting in general, the Abakaliki Anticlinorium. During the Campanian to Maastrichtian, a second depositional cycle during with the formation of the Proto Niger Delta took place. Locally, the deltaic conditions of deposition may have lasted into the Paleocene. This second cycle ended with a major Paleocene transgression which terminated the advance of the Proto Delta, thus separating it stratigraphically from the modern delta. A third cycle of deposition began in the Eocene and continues to present day. It is during this third cycle that the Modern Delta was formed (Short and Stauble, 1967) recognized three sub-surface stratigraphic units in the modern Niger Delta - Benin, Agbada and Akata formations.

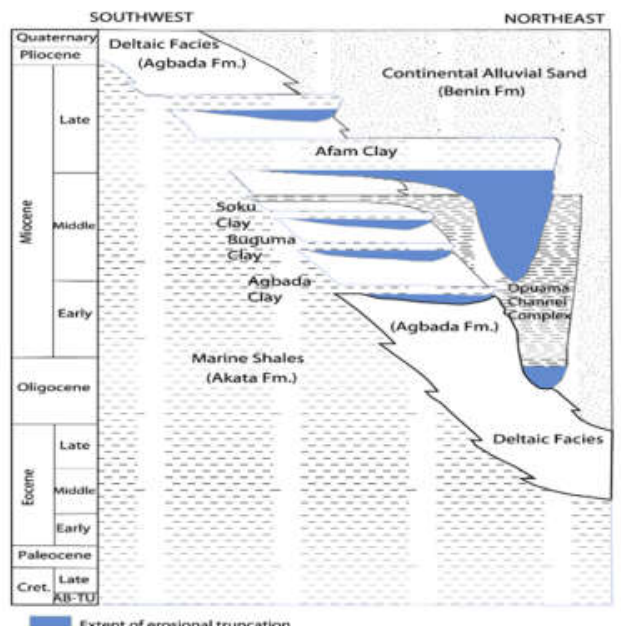

Fig 2: Stratigraphic column showing formations of the Niger Delta (Turtle et al 1999). Modified by Doust and Omatsola (1990).

Akata Formation: This is at the base of the delta. It is of marine origin and is composed of thick shale sequence (potential source rock), turbidite sands (potential reservoir in deep-water) and minor amounts of clay and silts. The approximate range of thickness is from $0-6000$ meters and the formation crops out subsea in the outer delta but is not seen onshore. This formation formed during lowstands when terrestrial organic matter and clays were transported to deep water areas characterized by low energy conditions and oxygen deficiency (Michele et al, 1990). It is estimated that the formation is up to 7000 meters thickness in the central part of the delta (Doust and Omatsola, 1990). It ranges from Palaeocene to Holocene in age and are over pressured.
Agbada Formation: The Agbada Formation is a sequence of sandstone and shales and consists of paralicsiliciclastics over 3700meters thick and represents the actual deltaic portion of the sequence. It consists of an upper predominantly sandy unit with minor shale intercalations and a lower shale unit which is thicker than the upper than the upper sandy unit. The formation is rich in micro fauna at the base decreasing upward and thus indicating an increase rate of deposition in the delta front. A fluviatile origin is indicated by the coarseness of the grains and poor sorting. The sequence is associated with sedimentary growth faulting and contains the bulk of the hydrocarbon reservoirs. The Agbada Formation occurs in the subsurface of the entire delta area and may be continuous with the Ogwashi-Asaba and Ameki Formations of Eocene-Oligocene age. It is up to 4000 meters thick in the central part of the delta thinning seawards and towards the delta margin, ranges from Eocene in the north to Pliocene/Pleistocene in the south and Recent in the delta surface. Major hydrocarbon accumulations are found in the intervals between Eocene and Pliocene age.

Benin Formation: Benin Formation extends from the west across the whole Niger Delta area and southward beyond the present coastline. It is over $90 \%$ sandstone with shale intercalations. It is coarse grained, gravelly, locally fine grained, poorly sorted, sub-angular to well-rounded and lignite streaks and wooden fragments. It is a continental deposit of probable upper deltaic depositional environment. Various structural units (point bars, channel fills, natural levees, backswamp deposits, ox-bow fills) are identifiable within the formation, indicating the variability of the shallow water depositional medium. In the subsurface, it is Oligocene in the north becoming progressively younger southwards. In general, it ranges from Miocene to Recent. The thickness is variable but generally exceeds $6000 \mathrm{ft}$. Very little hydrocarbon accumulations have been associated with the formation.

Materials: The cores used for this study were cut between 7015 and $9678 \mathrm{ft}$ with long uncored intervals. The long gaps are suspected to be mainly the shaly sections. The cores had been recorded as $411.95 \mathrm{ft}$ in total length. The material made available for description as contained in a total of 125 boxes, some of them only partially full, was only $315.90 \mathrm{ft}$. The cores had been resinated but have now all come loose because the resin had deteriorated over the thirty years of storage since acquisition. The cores have therefore undergone considerable physical and chemical damage perhaps also inflicted by less than careful 
handling during the many phases of transportation between Port Harcourt and the present storage place in Warri. Description was aided by templates for colour, grain size and trace fossil identification. Hand lens, brushes, chisel, dilute (10\%) hydrochloric acid and water were the other materials used.

Laboratory procedures: The study was carried out macroscopically, principally aided by X10 hand lens especially for granulometric studies. Dilute hydrochloric acid (10\%) was used to check for presence of carbonate cement and fossil fragments. Water was useful in making rough estimates of porosity and permeability by noting the ease of infiltration, especially as no core analysis data were provided. Water also proved useful in detecting the presence of even trace amounts of oil stain. A depth shift was carried out by comparing the drillers log with the wireline log. The result is shown in table 1. Data gathering on details of texture, structures and other features was carried out according to the format in the AppleCore software. Data entry and storage was done using Apple Macintosh power book switched on to core description option.

Table 1: Depth shifts of the cores of well XY-62 against the

\begin{tabular}{|c|c|c|c|}
\hline \multirow{2}{*}{$\begin{array}{c}\text { Core } \\
\text { no }\end{array}$} & \multicolumn{2}{|c|}{ Depths (ft) } & \multirow{2}{*}{$\begin{array}{l}\text { Shift } \\
\text { (Ft) }\end{array}$} \\
\hline & Core (Top) & Wireline & \\
\hline 2 & 7015 & 7015 & 0 \\
\hline 3 & 7038 & 7038 & 0 \\
\hline 4 & 7055 & 7055 & 0 \\
\hline 5 & 7492 & 7492 & 0 \\
\hline 6 & 7495 & 7495 & 0 \\
\hline 7 & 7524 & 7524 & 0 \\
\hline 8 & 7544 & 7544 & 0 \\
\hline 9 & 8034 & 8034 & 0 \\
\hline 10 & 8042 & 8042 & 0 \\
\hline 11 & 8057 & 8035 & +22 \\
\hline 12 & 8565 & 8565 & 0 \\
\hline 13 & 8582 & 8580 & +2 \\
\hline 14 & 8585 & 8585 & 0 \\
\hline 15 & 8588 & 8588 & 0 \\
\hline 16 & 8601 & 8601 & 0 \\
\hline 17 & 8622 & 8632 & -1 \\
\hline 18 & 8644 & 8642 & +2 \\
\hline 19 & 9567 & 9570 & -3 \\
\hline 20 & 9581 & 9581 & 0 \\
\hline 21 & 9600 & 9600 & 0 \\
\hline 22 & 9657 & 9648 & +9 \\
\hline
\end{tabular}

\section{RESULT AND DISCUSSION}

The Lithofacies: The principal exercise in core description and reporting is the identification of the lithofacies comprising the entire core length. The lithofacies, as defined by Reijers (1995), is the sum of all the primary (depositional) and secondary (diagenetic) characteristics of a sedimentary unit which distinguish it from the adjacent ones. The SPDC lithofacies scheme was used for the study (Table 2). The lithofacies is the basic building block of a given set of cores recovered from a well. The various individual segments of the total core recovery from well XY- 62 and made available for description have been grouped into 22 cores contained in 125 core boxes.

The XY - 62 cores consist of four lithofacies - Three sandstone and one mud rock Lithofacies (Fig. I and Table 3). The lithofacies are: 9i) Fine grained mmscale laminated sandstone (SI.f), (ii) Medium to coarse grained cm-scale cross-bedded sandstone (Sx.m) (iii) Pebbly sandstone (PS) and (iv) Bedded mudstone $(\mathrm{Mb})$.

Fine grained mm-scale laminated sandstone (Sl.f) lithofacies: The SI.f lithofacies occurs 17 times in the cores described, and makes up $129.40 \mathrm{ft}(40.83 \%)$ of the total core footage. The thicknesses of the individual uninterrupted occurrences range from 0.50 $\mathrm{ft}$ to $26.00 \mathrm{ft}$. There may actually be thick intervals since there are many mixing intervals, lost cores and uncored intervals. The Sl.f lithofacies is preferentially interbedded with the mud rock facies with contacts ranging between sharp and gradational. Some of its intervals may thus be described as noisy. It is less frequently in contact Iwith Sx.m lithofacies. Oil stain of fair to moderate intensity is present in almost all the intervals.

Petrography/Texture: The fine-grained $\mathrm{mm}$-scale laminated sandstone lithofacies is basically grey in colour. Modifications range from brownish to yellowish attributable to in situ ferruginization or postacquisition oxidation of ferrous iron to ferric state. Either way, the implication of dominant grey colour is insufficient oxygen circulation which may suggest at least partial anoxia. The modal grain size is consistently fine, with minimal extension into medium or very fine size grades. Size grading - normal or inverse - could not be clearly made out even on hand lens. However, the $30 \mathrm{ft}$ of core between $8034 \mathrm{ft}$ and $8068 \mathrm{ft}$ depths shows extreme size characteristics. The upper part has two pebbly horizons; the lower portion has thin clay layers. These intervals tend to modify the grain size. The Sl.f lithofacies is generally well sorted. The exception is the pebbly and clayey horizons which tend to reduce sorting to moderate. The grains of the Sl.f lithofacies are generally subangular. They also tend to be largely equant in shape. The clay content is estimated at between zero and 20\%. Considerable intervals are so clean as to be considered practically clay-free. Those sections interstratified with mudrock have the higher clay content. Textural maturity of the Sl.f lithofacies is therefore variable, although considerable intervals are clearly texturally mature. 
Table 2: The SIEP (Davies et al. 1997) Lithofacies Scheme - SPDC Practice)

\begin{tabular}{|c|c|c|c|}
\hline DOMINANT & CRAIN SLE & $\begin{array}{l}\text { DOMINANT } \\
\text { SEDIMENTARY STRUCTURE }\end{array}$ & $\begin{array}{l}\text { SEECONDARY } \\
\text { SEDIMENTARY STPUCTURE }\end{array}$ \\
\hline 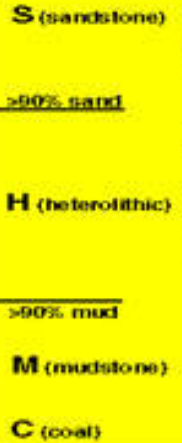 & 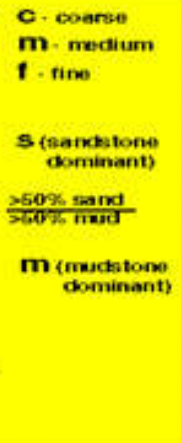 & 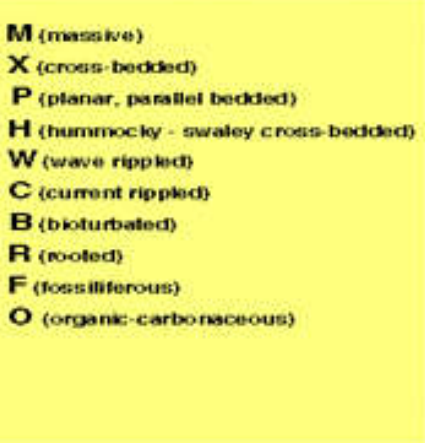 & $\begin{array}{l}\text { C (cement-general) } \\
\text { s (sklerfe) } \\
\text { /d (sont sediment deformed } \\
\text { stumped, sike, micro-tautied) }\end{array}$ \\
\hline
\end{tabular}

Table 3: Lithofacies frequencies in the cores of well XY-62

\begin{tabular}{lll}
\hline Lithofacies & \multicolumn{2}{l}{ Frequency } \\
\cline { 2 - 3 } & Ft & $\mathbf{\%}$ \\
Fine grained mm-scale laminated sandstone (Sl.f) & 129.40 & 40.83 \\
Medium to coarse grained cm-scale cross-bedded sandstone (Sx.m) & 112.00 & 35.34 \\
Pebbly sandstone (PS) & 13.90 & 4.39 \\
Bedded mudstone(Mb) & 61.60 & 19.44 \\
& 316.90 & 316.90 \\
\hline
\end{tabular}

Composition: The two compositional aspects of the Sl.f lithofacies are the framework elements and the void fillers. The former aspect consists of those mineral grains usually larger in size than 63 microns. This distinction is normally done in thin section, but examination of disaggregated samples with a X10 hand lens enables a rough estimate of the matrix which is essentially the detrital clay component. Feldspars and rock fragments were not identified in the Sl.f lithofacies perhaps mainly because of the limitations of the study methodology. They are however usually minor to absent in the lithofacies of the Niger Delta which are second or even third-cycle sediments. They may be assumed to have chemically decayed and been transformed into clay, enhancing the matrix frequency. Such disintegration leaves quartz as virtually the sole framework mineral of the lithofacies. An accessory component often considered in relation to framework material is mica. It is present in the lithofacies as tiny flakes of muscovite usually lying parallel to lamination and therefore more easily observed on stratification planes.

Other obvious components of the SI.f lithofacies include carbonaceous matter and heavy minerals. These are within the clay matrix in the less clean intervals. Carbonaceous matter occurs as black streaks, irregularly shaped clots, interstitial fills and grain coatings. Heavy minerals were not definitively identified but some commonly observed black grains are thought to be ilmenite, which is often the most frequently occurring non opaque heavy species in the Niger Delta. The chemically formed void fillers, i.e. the cementing materials, are the ferruginous and calcareous components. The iron oxides have imparted the yellow to brown colour to the background grey colour of the lithofacies. Hematite and limonite are thought to be the main mineral species. The calcareous cement consists of calcite disseminated in the interstitial spaces and therefore not macroscopically observed. Rather, vigorous reaction with dilute (10\%) hydrochloric acid testifies to its presence. A rather restricted component of the SI.f lithofacies is fossil fragments; they are found only between the interval $7550 \mathrm{ft}$ and $7560 \mathrm{ft}$. The shells are chemically weathered, disarticulated and randomly oriented.

Classification and Maturity: The commonly used classification system of sandstones (Pettijohn, 1975) applies the matrix frequency for separating arenites from wackes. The matrix content of the SI.f lithofacies, as shown in the clay percentage column of the strip log, ranges from practically zero to $40 \%$. The $15 \%$ boundary between arenite $(<15 \%)$ and wacke lies inside this range. The SI.f lithofacies therefore spans the whole sandstone classification range and may be regarded as both arenite and wacke. The apparent (or assumed) absence of feldspars and rock fragments implies that the lithofacies consists of both quartz arenite and quartz wacke. The bearing of this on interpretation of the depositional environment will be discussed later. The assumed absence of feldspars and 
rock fragments also implies that the compositional maturity of the SI.f lithofacies is high.

Diagenesis: The degree of post depositional conversion of loose sediment to rock which the SI.f lithofacies has undergone is to be considered in two perspectives - physical and chemical. The degree of consolidation ranges from poor to moderate which makes the lithofacies generally friable. The physical aspect has therefore not proceeded far enough to produce a properly indurated rock. This may be attributable in part to insufficient overburden. As already indicated, the yellow and brown modifiers of the background grey colour are due to ferruginous cements, notably hematite and limonite. The other cement is calcite. In terms of binding the grains together, these minerals are ineffective. They are however regarded as cement which by definition means a post depositional precipitate from groundwater, through pressure solution, or by recrystallization from matrix. The diagenetic status of the lithofacies is thus in the very early stages. This has perhaps enhanced the reservoir qualities of the lithofacies, enabling it to accommodate a substantial volume of the hydrocarbon charge in the XY field. Sedimentary Structures: The SI.f lithofacies exhibits mainly physical sedimentary structures, rarely the biogenic, and none of the chemical types. Even the physical structures are characteristically low in diversity and often subtly rather than boldly expressed. Such bedforms as ripples and parting lineation were not observed. Boundaries with other lithofacies range from sharp through gradational to uncertain, especially where sections are missing or uncored. Within the lithofacies proper, beds are in either sharp or gradational contact. Stratification structures are dominant and include parallel lamination, crossbedding, and flaser bedding. Parallel lamination is expressed as a stack of flat strata in which the various stratification units are demarcated by subtle colour and/or grain size differences. Such a structure is commonly produced by deposition on a plane bed in rapidly flowing water in the upper flow regime, or in the lower flow regime by suspension dropout with little or no traction. The former alternative is more likely in view of the common occurrence of granule to pebble size grains. The SI.f lithofacies, especially in the shallower cores, shows some low-angle crosslaminated horizons. These are small scale features attributable to the action of currents strong enough for traction to move cohesion-less fine sand already deposited from suspension. On the other hand, if current velocities generally sufficient for an upper regime plane bed were intermittently decreased, ripples would be interbedded with low- angle crosslaminae. It should be noted that the limited view afforded by a core would not allow for the observation of the full lateral extent of some structures such as wave ripples and hummocky cross-strata, These would appear as parallel lamination, usually slightly curved i.e. concave or convex up. Flaser lamination is not common. It occurs in the SI.f lithofacies around the $7550 \mathrm{ft}$ depth and deeper. The flasers range from simple mud streaks to wavy and bifurcated wavy types. Their formation is attributed to alternating periods of sediment supply i.e. rhythmic or periodic, as in delta fronts or river flood plains. Trace fossils are rare in the lithofacies. Only one occurrence of a doubtful Ophiomorpha was observed - at the $8050 \mathrm{ft}$ depth. Occurrence of rootlets is also restricted, being found at only one depth: $9613 \mathrm{ft}$. Thus trace fossils in the SI.f lithofacies are extremely low in both diversity and abundance.

Lithofacies Code: The characteristics of SI.f lithofacies established above may be summarized as follows:

$$
\text { SI.f }=\mathrm{S} 2, \mathrm{TsT}, \mathrm{TmlO}, \mathrm{gn}, \mathrm{p}+\mathrm{xl}
$$

Where, $\mathrm{S} 2=$ Fine sandstone; $\mathrm{TsT}=$ Well sorted; Tm10 $=$ Detrital clay averaging $10 \%$; gn $=$ No apparent grain size trend; Ip = Parallel lamination; $\mathrm{xl}=$ Some lowangle cross lamination

Depositional Environment: The SI.f lithofacies composition shows a widely varying clay content; i.e. it has both clean and dirty sections. The practically clay-free sections, which also generally show good sorting, could be assigned to wave-washed settings while the more clayey horizons are from slightly deeper water, assignable to an upper shoreface setting. This latter variety also tends to show other evidence of deepening water - such as shale/mud rock interbedding, shell fragments and calcite cement. The dominance of parallel lamination indicates flow in the upper flow regime as well as suspension dropout during no flow in the lower flow regime. The latter is ruled out since pebbles, granules and rip-up clasts are present and the clean (clay-free) sections comprise a considerable footage. The minor presence of lowangle cross-lamination is an indication that stream power in the upper regime of flow occasionally diminished to the lower regime that allowed smallscale ripple formation and migration. The notion that the parallel disposition of the lamination might be apparent rather than real allows to suggest that there might actually have been formed, a mix of wave ripples grading back and forth into low- angle crosslamination. This is the swash cross-lamination well known in foreshore settings (Harms et al., 1982). The $\log$ expression of the Sl.f lithofacies both on wireline 
and core $\log$ is in small- scale upward fining cycles. On a gross scale the log signature is noisy, there being frequent $10-15 \mathrm{~cm}$ ) thick shale breaks that only probably locally partition the rather thick, hydrocarbon-charged reservoir.

Medium to coarse-grained, centimeter scale crossbedded sandstone (Sx.m) lithofacies: The Sx.m lithofacies was encountered in fourteen horizons in the XY-62 cores and constitutes $112 \mathrm{ft}(35.34 \%)$ of the cores described (Table 3; Fig. 3). It occurs mainly from $8582 \mathrm{ft}$ down to $8991 \mathrm{ft}$ depth with several feet of missing material.

Petrography: As already observed, the Sx.m lithofacies is remarkably lithologically homogeneous, the only intervening lithotype - shale - being volumetrically minor and far between in occurrence. Pebble occurrence is common both in random distribution and as pebble layers two or three grains thick.

Texture: The basic colour of the Sx.m lithofacies is grey. Occasional browns are present. The modifiers range from light yellowish to dark brownish. These modifiers are thought to reflect the extent of oxidation of the interstitial ferruginous cements. The modal grain size is medium. With the sorting that is consistently good, this modal size has little or no variation (i.e. very low standard deviation). However, this characteristic grain size does not take account of the randomly distributed grains of granule and pebble size. Roundness and sphericity were not assessed under a petrographic microscope. What could be made out with a X10 hand lens is thought to be subrounded and equant (i.e. equidimensional). Similarly, any preferred orientation of the sand and the larger grains could not be observed. The detrital clay content of the lithofacies ranges from zero to $20 \%$. By convention, those intervals containing over 5\% clay are regarded as texturally immature. Since such intervals constitute the bulk of the lithofacies, textural immaturity is concluded for the lithofacies.

Composition: The constituents of sandstone are broadly subdivided into framework elements and the void fillers. The former should normally consist of quartz, feldspars and rock fragments. In the Sx.m lithofacies of the XY - 62 cores, feldspars and rock fragments was not identified. This could be on account of the study methodology; X-10 hand lens may not have been adequate. But there is the likelihood that these two components are actually virtually absent. This view may be supported by the well known dearth of labile components in second and third cycle sediments. The Niger Delta facies are largely third cycle deposits. The lithic fragments observed around the $8990 \mathrm{ft}$ depth appear to be an isolated occurrence and may actually be classified as an intraformational conglomerate. Quartz is by far the dominant mineral species in the framework composition. Indeed, but for some minor content of mica (muscovite) the framework aspect may be regarded as monomineralic. No detailed petrographic study could be carried out on the quartz but it may be envisaged that the majority of the grains would be monocrystalline with subordinate 2 - 3 crystal polycrystalline grains. The void fillers are the matrix and cement. The former consists of mainly clay and silt size grains of quartz and heavy minerals which are usually less than 63 microns in size. Of the heavy minerals only occasional black grains thought to be ilmenite were observed. Other accessory materials which form part of the matrix are carbonaceous matter which occurs as both grain coatings, randomly distributed interstitial masses or as fine layers parallel to, and emphasizing, the lamination. Cement is essentially iron oxide. Occasional minor occurrences of gypsum efflorescence were also recorded. The iron oxide is thought to be mainly ilmenite, with subordinate limonite. The minerals have imparted the brighter colors to the dull background grey, warranting the use of such terms as "light yellowish grey" or "dark brownish grey" etc.

Classification and compositional maturity: The ternary system of sandstone classification first distinguishes the arenites (less than $15 \%$ matrix) from the wackes ( $15 \%$ or more matrix). On this basis most of the Sx.m lithofacies of the XY -62 belongs to the arenite class, since $5-10 \%$ appears to be the common estimate of the detrital clay content. The next step in the classification applies the framework mineralogy. The virtually monomineralic framework composition assigns the lithofacies to the quartz arenite class, since feldspar and rock fragments were not identified. Some systems replace rock fragments with mica but this does not change anything since the frequency of muscovite is insignificant. With quartz as virtually the sole component of the framework aspect of the Sx.m lithofacies, the level of compositional maturity is so high that it should be regarded as mineralogically supermature.

Diagenesis: The two aspects of diagenesis here considered are physical and chemical. The physical aspect assesses the degree of consolidation effected by compaction. The Sx.m lithofacies has undergone little or no consolidation due to compaction. The degree of consolidation as indicated in the appropriate column on the strip log varies between poor and moderate. This means that most of the lithofacies interval is friable, i.e. unconsolidated or weakly consolidated. 
The chemical aspect of diagenesis appears to be at such an early stage that it has not complemented compaction. Thus even though the presence of iron oxide cements is clearly evident, effective binding of grains has not taken place. Thus the so-called cement may actually be present only as grain coatings. However, the obvious absence of cement as interstitial filling has enhanced the petrophysical properties of the lithofacies, as shown by the good to very good oil stain. The depositional primary porosity had virtually been left intact, allowing for a high reservoir quality.

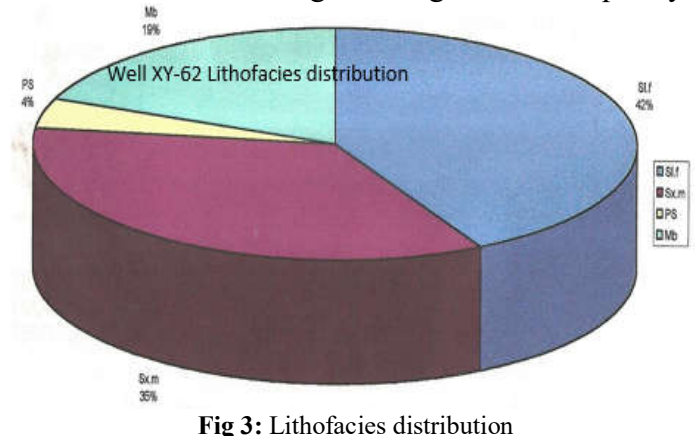

Sedimentary structures: Of the three classes (physical, chemical and biogenic), of sedimentary structures characteristic of sandstones; only the physical type was noted in the Sx.m lithofacies of the XY- 62 cores. Even within the physical class present, only parallel lamination is observed. Set boundaries are generally sharp, being marked by grain size or colour differentiation or differential concentration of carbonaceous matter. Given the prevalence of medium grain size and the presence of small to large pebbles, the depositional hydrodynamics for lithofacies would fall within the upper flow regime. Thus the parallel lamination must have been formed as upper stage plane beds. Such laminae are known to result from pulsating net deposition over the plane bed surface in shallow water. Flat-bed mode of transport is easily envisaged for unidirectional flow, but waves are also known to lead to the development of flat beds - by way of unidirectional back-wash and high-energy waves beyond the surf zone. The formation of the Laminae would also result in grain-size segregation. Fluctuations in flow strength would result in size segregation which produces layers of moving grains with differing size characteristics, producing laminae when movement ceases.

Lithofacies Code: The summary of the characteristics of the Sx.m lithofacies, is as follows:

$$
\text { Sx.m..m = S3+4, Ts5-6, gn, lp }
$$

Where, S3+4 = Sandstone, medium grained with granules and pebbles; Ts5-6 = Sorting - moderate to good; gn = No grain size trend apparent; Ip = Parallel lamination

Depositional Environment: From the characteristics of the Sx.m lithofacies already outlined under texture, composition and sedimentary structures, the depositional environment may be deduced. The depositional energy represented by the medium pebbly texture may range from moderate to high. Flow in the upper regime would be the only type that can move pebbles and form plane beds now preserved as parallel lamination. From the strip log, no particular motif or grain size trend is dominant, although very short (5ft) coarsening - and fining - upward cycles are present near the bottom of the cores. The textural maturity is low at $5-20 \%$ clay content. However whole stretches with practically no clay matrix may be taken as evidence of cleaning processes that operated in the depositional setting. Wave activity in the surf zone may therefore be invoked. Thus a wave-influenced shoreline may be suggested as the depositional setting for the Sx.m lithofacies of the XY - 62 cores.

Pebbly Sandstone (PS) lithofacies: The third sandstone lithofacies of the XY- 62 cores is the Pebbly Sandstone. It is volumetrically a relatively minor lithofacies. It occurs only in three horizons and constitutes a relatively insignificant $4.39 \%(13.90 \mathrm{ft})$ of the total footage of the XY - 62 cores. The most important interval, though truncated by a lost core, is $8.50 \mathrm{ft}$ thick and is twice interbedded by conglomerate proper. The lithofacies has sharp contacts with both SI.f and mudstone but not the Sx.m lithofacies. In the 8034 - $8040 \mathrm{ft}$ interval, it is interbedded with the SI.f lithofacies.

Petrography: Within the pebbly sandstone lithofacies, a subordinate rock type can be distinguished as conglomerate. This is volumetrically minor but sedimentologically significant, being an indicator of higher energy in the depositional setting.

Texture: The PS lithofacies ranges in colour from yellowish brown to brownish grey. These colour shades are thought to reflect the state of oxidation of iron cements. The critical distinguishing textural parameter is the grain size range (sorting) which varies from fine to coarse, with a content of large particles ranging from small to large pebbles $(<32 \mathrm{~mm}$ i.e. 5 phi). The modal grain size i.e. the dominant size class or population has been estimated to be coarse. This has to be qualified by sorting which is essentially poor. No size grading trends - inverse or normal - were observed. Roundness is low on the average but 
increases to near perfect in the conglomerate horizons because of the inherent tendency of larger particles to become more easily rounded than the associated sandsize grains. Sphericity is generally low to moderate on account of the preponderance of bladed and elongate forms. The combination of these attributes still allows for sufficient porosity and permeability to make the PS lithofacies a good reservoir. Imbrication, the principal fabric element expected in the pebbles of the conglomerate horizons, was not observed. Perhaps the core cut did not pass through the real orientation that would make Imbrication easily observable. The detrital clay content is practically zero. A short interval underlying a relatively thick mud rock interval has up to $20 \%$ clay matrix. Excepting for this short interval, the PS lithofacies should be taken as texturally supermature. Packing of the grains may be regarded as clast-supported in view of the virtual absence of matrix.

Composition: The framework aspect appears to be the sole component of most of the PS lithofacies. The matrix component containing clay and the $<0.63 \mathrm{~mm}$ grains are practically absent. No feldspars and rock fragments were identified in the pebble and sand size grains. The PS 1 ithofacies is thus virtually monomineralic with quartz as the sole detrital mineral. Occasional mica (muscovite) flakes are present. Ripup clasts are mud chips derived from the immediate depositional area i.e. intraformational conglomerate. Cement can be inferred from the variety of strong colors ranging from yellow to brown. It occurs solely as grain coatings since it is not observed as interstitial masses.

Classification and Mineralogical Maturity: The absence of matrix classifies the PS lithofacies as arenites, although the horizon with $20 \%$ matrix should place it in the wacke class. The lithofacies therefore ranges from quartz arenite to quartz wacke. The absence of feldspars and rock fragments makes the lithofacies mineralogicaly super mature

Diagenesis: The pebbly sandstone horizons are strongly consolidated. Rather curiously, the interbedding conglomerates are less so, being only moderately consolidated. The chemical aspect of diagenesis may only be inferred to have transpired by way of iron oxide (hematite) precipitation, as indicated by the variety of browns and yellows. The diagenetic stage may be regarded as intermediate, although there is no adverse effect on the reservoir quality.

Sedimentary structures: The pebbly sandstone lithofacies contains only the physical type of sedimentary structures. No burrows (biogenic) or chemical structures were observed. Even the physical type is invariably only flat stratification. The conglomerate interbeds are apparently massive i.e. unstratified. The demarcation between strata is somewhat crude, diffuse or gradational and has been detected using subtle textural changes.

Lithofacies Code: The characteristics of the pebbly sandstone lithofacies may be represented as follows:

$$
\mathrm{PS}=\mathrm{SCI}+2, \mathrm{Ts} 3, \mathrm{gn}, \mathrm{Ip}
$$

Where, $\mathrm{SCI}+2=$ Sandstone with granules and pebbles up to $32 \mathrm{~mm}$ in size; Ts3 = Poor sorting; gn = No particular grain size trend; Ip = Flat stratification

Depositional Environment: The pebbly sandstone lithofacies is a high-energy component of a depositional setting which also has fine sandstones and mud rocks. The predominantly clean texture i.e. virtual absence of clay matrix is an indication of winnowing which easily occurs on foreshores. Flat stratification is also an attribute of high-energy environments represented by beaches. The less clean horizons may be explained as having been deposited basinward or landward of the foreshore.

Bedded Mudstone (Mb) lithofacies: This is the only mud rock contained in the cores of XY- 62. It occurs in 14 horizons and makes up $61.60 \mathrm{ft}$ (19.44\%) of the total core length. The horizons range in thickness from $1 \mathrm{ft}$ to $11.50 \mathrm{ft}$, with the thicker ones in the lower cores. Boundaries with other lithofacies are invariably sharp. It is worth noting that the sandstones over-and underlying the bedded mud rock intervals are all oilstained. This implies that these mud rock horizons are not seals in the XY field. They have only compartmentalized the reservoirs.

Petrography: The mudstones of the XY - 62 cores range from very light grey claystone to grey siltstones and black shales. Rough estimates of their clay content range between 50 and $70 \%$. The balance is mainly silt size grains. Accessory components include masses of carbonaceous matter, plant fragments and gypsum which occurs as whitish efflorescent masses present on core cut surfaces and on lamination planes. Consolidation is variable - ranging from moderate in the claystones to strong in the shales. The interval between $9602 \mathrm{ft}$ and $9613 \mathrm{ft}$ shows a chemical diagenetic feature which occurs as an intricate meshwork of reddish brown (dusky red) threads. They may be ferrugenised plant fragments.

Sedimentary structures: The entire mud rock sub facies are depicted on the strip log as moderately to 
abundantly parallel laminated. It is actually the only sedimentary structure ' $n$ most of the bedded mudstone horizons. It may indeed be assumed to have been accentuated into fissility in the shales. In both parallel lamination and pure fissility, the stratification planes are marked by the presence of mica (muscovite) flakes.

Lithofacies Code: The bedded mudstone lithofacies can be represented as follows:

$$
\mathrm{Mb}=\mathrm{M}, \mathrm{Tm} 50-70, \text { gn, bmm-cm }
$$

Where, $\mathrm{M}=$ Mudstone; Tm50-70 = Detrital clay content from $50-70 \%$; gn $=$ no discernible grain size trend; bmm-cm $=$ Stratal thickness in $\mathrm{mm}$ to $\mathrm{cm}$

Depositional Environment: The bedded mudstones of the XY -62 cores are thought to have been deposited in continental setting, specifically in a lagoonal environment. The absence of evidence of marine depositional earmarks leads to this assertion. Additionally, the associated sandstones, which have been shown to be mostly of foreshore depositional origin, may be assumed to be the basinward facies in a marginal marine depositional sub environment.

Lithofacies Association: The four lithofacies discussed above - SI.f, Sx.m, PS and Mb - belong to two broad classes: sandstones and mud rocks. The sandstones are characteristically clean, parallel laminated and blocky in motif. The three lithofacies are assigned to the coastal barrier lithofacies association. The bedded mudstone is assigned to the back barrier lagoonal delta lithofacies association.
Conclusion: The four lithofacies of the XY - 62 cores represent a depositional energy spectrum that ranges from low (mudstone) to considerably high (pebbly sandstone). The sandstones are mostly clean and parallel laminated. They have been assigned to the coastal barrier lithofacies association, an environmental setting in which wave energy is the driving force for the hydrodynamics.

\section{REFERENCES}

Doust, H; Omatsola, E (1990). Niger Delta, in, Edwards, JD and Santogrossi, PA, eds., Divergent/Passive Margin Basins. AAPG Memoir 48 239-248

Harms, JC; Southard, JB; Walter, RG (19820: Structures and sequences in clastic rocks. SEPM Short course No. 9.

Pettijohn, FJ (1975): Sedimentary Rocks, 3rd Ed., Harper and Row, Pp 828

Reijers, TJA (1975): Lithofacies and their associations in the Tertiary Niger Delta, Nigeria

Reyment, RA, (1965). Aspects of the geology of Nigeria, Ibadan University Press, Ibadan, Pp. 145

Short, KC; Stauble, AJ (1967). Outline of geology of Niger Delta: AAPG Bull.. 51.761-799.

Tuttle, MLW; Charpentier, R; Brownfield, ME (1999). The Niger Delta Petroleum System: Niger Delta Province, Nigeria, Cameroon and Equatorial Guinea, Africa. USGS Open-File Report 99-50-H 